\title{
EDITORIALES
}

\section{Un buen servicio ya no basta}

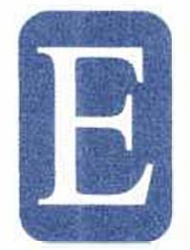

1 servicio que ofrece una institución hospitalaria debe ser extraordinario para poder asegurar rentabilidad, permanencia en el mercado y generar competencia sobre una base de valores diferentes al precio.

La salud en Colombia se ha transformado en un negocio como cualquier otro, en el cual el paciente se ha convertido en un «cliente»; pero en la prestación de servicios de salud la situación debe ser distinta, pues existen factores relevantes como la enfermedad y el dolor, que hacen al paciente vulnerable e intolerante y convierten a sus familiares, en caso de un desenlace fatídico, en investigadores de los responsables dentro del personal médico y paramédico.

Dadas estas características, nosotros en nuestra institución, como Hospital Universitario de Tercer Nivel, debemos iniciar un mejoramiento integrado hacia la excelencia, preservando los valores de la institución y la fe en la capacidad de la gente que la conforma.

De otra parte, la calidad debe ser una «cultura» ya que es definida por el usuario y debe ser de responsa- bilidad de todos y cada uno de los funcionarios. Por esta razón, es nuestra misión cumplir las especificaciones para la prestación de un servicio excepcional al cliente, basadas en el liderazgo, la realización de encuestas de satisfacción de mercado (sistema de información sobre la calidad del servicio), la creación de estrategias de servicio, la integración y el trabajo en equipo, la utilización de tecnología de punta, el desarrollo de sistemas de indicadores y el desarrollo de funciones con personal capacitado.

Por todo lo anterior, hemos propuesto como meta para el 2001, participar en el concurso organizado por la Fundación GEOS por el premio de la «CALIDAD EN SALUD», el cual desde ya, no sólo representa beneficios por el simple hecho de competir, sino que, adicionalmente, permitirá iniciar la elaboración de un plan evaluativo de mejoramiento en calidad, cuyo único propósito es lograr nuestro sueño de ser excelentes en la prestación de servicios de salud.

Laima Lucía Didziulis G, M.D. Directora Médica Hospital de San José 